\title{
Do sustainable palliative single fraction radiotherapy practices proliferate or perish 2 years after a knowledge translation campaign?
}

\section{Shaheer Shahhat}

University of Manitoba Max Rady College of Medicine

Nikesh Hanumanthappa

CancerCare Manitoba

\section{Youn Tae Chung}

University of Manitoba Max Rady College of Medicine

James Beck

CancerCare Manitoba

Rashmi Koul

CancerCare Manitoba

\section{Bashir Bashir}

CancerCare Manitoba

\section{Andrew Cooke}

CancerCare Manitoba

\section{Arbind Dubey}

CancerCare Manitoba

Jim Butler

CancerCare Manitoba

Maged Nashed

CancerCare Manitoba

\section{William Hunter}

CancerCare Manitoba

\section{Shrinivas Rathod}

CancerCare Manitoba

\section{Aldrich Ong}

CancerCare Manitoba

\section{Kim Tran}

Canadian Partnership Against Cancer

Julian Oliver Kim ( $\nabla$ jkim7@cancercare.mb.ca )

University of Manitoba Faculty of Medicine: University of Manitoba Max Rady College of Medicine https://orcid.org/0000-0003-0332-2024 
Research

Keywords: radiotherapy, time, campaign, derived, utilization

Posted Date: October 29th, 2021

DOl: https://doi.org/10.21203/rs.3.rs-956240/v1

License: (c) (i) This work is licensed under a Creative Commons Attribution 4.0 International License.

Read Full License 


\section{Abstract \\ BACKGROUND}

There is a paucity of data regarding the time-dependent effects of knowledge translation (KT) campaign derived Radiation Oncologist (RO) prescription behaviour. In early 2017, the XXXX and XXXX undertook a comprehensive KT campaign to improve utilization of single fraction radiotherapy (SFRT) over multiple fraction radiotherapy (MFRT) in accordance with clinical guidelines for palliative management of bone metastases. The campaign significantly increased short-term SFRT utilization. We assess the timedependent effects of KT-derived SFRT utilization 12-24 months removed from the KT campaign in a Canadian Provincial Cancer Program.

\section{METHODS}

This retrospective, population-based cohort study identified all patients receiving palliative radiotherapy for bone metastases in XXXX from 1 Jan 2018 to 31 Dec 2018 using provincial radiotherapy databases. Baseline characteristics were tabulated by fractionation schedule. The proportion of patients treated with SFRT in 2018 was compared to 2017 levels overall and by prescribing RO. Logistic regression analyses identified risk factors associated with MFRT receipt.

\section{RESULTS}

In $2018,1,008$ patients received palliative radiotherapy for bone metastasis, of which $63.3 \%$ received SFRT, a small overall increase in SFRT use over 2017 (59.1\%). However, 41.1\% of ROs demonstrated yearover-year decreases in SFRT utilization, indicative of a time-dependent loss of SFRT prescription habits derived from $\mathrm{KT}$.

\section{CONCLUSION}

Although SFRT use increased slightly overall in 2018, evidence of compliance fatigue was observed suggestive of a time-perishing property of RO prescription behaviours derived from KT methodologies. These findings highlight the need for additional longitudinal KT reinforcement practices in the years following KT campaigns.

\section{Contributions To The Literature Statement}

- Knowledge Translation (KT) interventions have been demonstrated to increase short-term utilization of Single Fraction Radiotherapy by radiation oncologists for palliative management of bone metastases 
- There is a paucity of literature regarding efficacy of KT interventions in Radiation Oncology beyond the immediate follow-up period

- We conducted a retrospective, population-based, assessment of the impact of a KT intervention in the second year following a KT intervention

- We observed evidence of compliance fatigue amongst radiation oncologists in the second year following the KT intervention

- The findings of this study suggest the need for long-term reinforcement of KT messaging in the radiation oncology milieu

\section{Background}

There is significant evidence from high-quality published randomized clinical trials that single fraction radiotherapy (SFRT) is a more appropriate dose-fractionation choice when compared to multiple fraction radiotherapy (MFRT) for the palliative management of painful, uncomplicated bone metastases (1). Several advantages of SFRT over MFRT include: non-inferior analgesic effects and post-treatment qualityof-life (1-4), non-inferior toxicity profiles $(3,5)$, greater logistical convenience and less treatmentassociated out-of-pocket expenses for patients $(6,7)$, lessened resource impacts to healthcare systems on account of lower costs (7-9), and less linear accelerator time and radiotherapist workload per patient. For these reasons, SFRT is recommended over MFRT for treatment of uncomplicated bone metastases by many respected clinical guideline groups (10-12). Despite its advantages, SFRT remains clinically underutilized for the management of patients with bone metastases worldwide (13-15). The reasons for this knowledge-to-action gap between evidence-based recommendations for SFRT and real-world underutilization of SFRT are numerous and include unfounded fears of inadequate analgesic effect and increased toxicity with SFRT, lack of understanding of the published literature, and physician remunerative factors in some jurisdictions (13-14).

Knowledge translation (KT) campaigns serve to mitigate recognized knowledge-to-action gaps which exist between published evidence and guidelines with clinician decisions (16). X et. al. determined previously that a high proportion of patients in XXXX with bone metastases were treated with MFRT (68.8\%) rather than SFRT (31.2\%) (15). This finding inspired the development of a KT pilot project jointly championed by the XXXX and XXXX (a Canadian provincial cancer program) which was designed to encourage improvements in SFRT utilization in the day-to-day practice of radiation oncologists (ROs) province-wide. The KT campaign was carried out in early 2017 and was built around the Choosing Wisely Canada (CWC) (17) national campaign recommendation in support of the use of SFRT over MFRT (18). The impact of the KT campaign during the calendar year following the intervention (2017) were immediate and pervasive whereby every single radiation oncologist in the province increased their proportion SFRT utilization when compared to the pre-intervention period (2016). In the 12 months following the KT campaign, the provincial utilization of SFRT increased from $38.0 \%$ (2016) to $59.1 \%$ (2017) for all bone metastases, and $46.4 \%$ (2016) to $67.7 \%$ (2017) for uncomplicated bone metastases, 
representing year-over-year increases of $21.1 \%$ and $21.3 \%$, respectively (19). No further active KT interventions were mandated after the conclusion of the KT pilot project in 2017.

The purpose of this study was to assess the impact of the KT campaign beyond its immediate impact period of 12 months to the period spanning 12-24 months post-intervention and to determine if there was any aspect of time-dependent loss of KT-derived RO SFRT prescribing behaviour. Studies in the literature assessing KT interventions for effectiveness typically only extend for a short follow-up after the intervention $(20,21)$. Another jurisdiction has previously reported that their KT interventions for ROs resulted in only a transient increase in SFRT utilization in the first four years post-intervention and declined over the next four years almost to pre-intervention baseline (22). Therefore, we aimed to continue to quantify SFRT use in XXXX in 2018 and assess the long-term sustainability of KT interventions in the radiation oncology milieu.

\section{Methods}

$\mathrm{XXXX}$ is the provincially mandated and publicly funded sole provider of RT services for the Canadian Province of XXXX, with a catchment population of approximately 1.4 million persons.

\section{Knowledge Translation Intervention Summary.}

The KT campaign pilot project and the interventions which it employed have been described previously in the report of the 2017 calendar year (19). Briefly, the KT campaign consisted of the following elements: 1) Educational outreach visits/grand rounds with external subject matter experts who reviewed the evidence and guidelines in support of SFRT utilization for painful bone metastases, 2) Consensus meetings to review all of the pertinent evidence employing a cooperative Socratic style of dialogue in which questions were asked of the group members with respect to their opinions on the evidence, allowing members to make their own conclusions on the data, 3) Follow-up surveys to measure intent of adopting guidelines, 4) Data collection, analysis, of SFRT utilization which was then presented to participating ROs in an anonymous manner at the group level. The KT campaign was based on the CWC recommendation: "Don't recommend more than a single fraction of palliative radiation for an uncomplicated painful bone metastasis" (18). In accordance with Cheon et. al., an uncomplicated bone metastasis was defined as a painful bone metastasis unassociated with impending or existing pathologic fracture, spinal cord compression, or cauda equina compression (23). The KT campaign was carried out in Early 2017.

\section{Study Aim:}

This study aimed to determine if KT-derived RO prescription behaviour for SFRT utilization declined in the long term (during the second year removed from the KT intervention), following the KT intervention.

Specifically, we sought to determine if during 2018 there was any changes in the utilization of SFRT over the reported 2017 levels (59.1\% for all bone metastases; $67.7 \%$ for uncomplicated bone metastases). We also sought to identify risk factors associated with receipt of MFRT during the same time period.

\section{Data Sources and Data Extraction:}


All courses of palliative RT for a bone metastasis in XXXX during the study period (1 Jan 2018 to 31 Dec 2018) were identified using the XXXX radiotherapy database. This prospectively maintained electronic administrative database is populated with variables entered into the RT treatment directive completed by a prescribing RO prior to the initiation of any RT-related treatment procedures. The following variables were extracted from this database for each course of RT: primary tumor type (ICD-10 diagnostic code), patient sex, patient age at time of RT, RT dose, RT fractionation, and prescribing RO. The remaining characteristics were extracted from the XXXX electronic medical records including anatomic treatment site, Eastern Cooperative Oncology Group (ECOG) performance status, radiotherapy (RT) treatment intent (post-operative vs palliative; post-operative intent RT was defined as RT within 60 days after any orthopedic surgery intervention (e.g., open reduction, internal fixation surgery), and Charlson Comorbidity Index. Diagnostic imaging reports and the electronic medical records were used to classify each bone metastasis as complicated or uncomplicated by determining the presence or report of a fracture in the targeted bony structure, spinal cord compression, or cauda equina compression. Patients were excluded from analysis if the site receiving RT was predominantly a soft tissue metastasis where the bone metastasis was only a minor component of the target volume (defined as a bone metastasis that composes $<20 \%$ of the target volume as determined using each patient's CT simulation scan). Patients treated with stereotactic body radiotherapy (SBRT) for bone metastases during 2018 were excluded from analysis since dose fractionation choices for SBRT patients are independent of the CWC guidelines.

\section{Statistics}

Baseline characteristics were tabulated for the entire cohort and by fractionation schedule (SFRT vs MFRT). Differences in distribution of baseline characteristics by fractionation schedule were assessed using standard statistical tests (chi-squared, student t-test). The proportion of SFRT courses in 2018 was compared to the proportion of SFRT courses in 2017 using the one-sample z-test test for proportions. The proportion of SFRT courses prescribed by each individual RO was visualized with bar graphs for both uncomplicated and all bone metastases. The difference in proportion of bone metastases treated with SFRT were tabulated year-over-year for each individual oncologist, expressed as a percentage change. Baseline variables were assessed for potential associations for receipt of MFRT using univariable logistic regression analysis. A multivariable logistic regression model (Model 1) was built using the 2017 data employing a forward, stepwise approach. Variables with univariable associations of $p \leq 0.2$ were considered for inclusion in the multivariable model and variables were assessed for collinearity in the model by assessing change in model variance during the forward stepwise selection process. A separate multivariable model (Model 2) was built including the data from the 2017 calendar year (previously reported) merged with the 2018 data with a variable added for year of treatment (2017 vs 2018) in the model. The purpose of this separate model was to assess the odds ratio for receipt of MFRT by treatment year, adjusting for all the other potential confounding variables used in the 2017 logistic regression model. Multivariable associations with $p \leq 0.05$ were considered statistically significant for this study. All analyses were conducted using STATA version 15 (Statacorp, College Station, Texas, USA). 
This study was conducted with the prior written approval of the University of XXXX Health Research Ethics Board (Approval \#: HS20808), and the XXXX Research Resource Impact Committee (Approval \#: 2017-020).

Our study adheres to the SQUIRE 2.0 reporting guideline. Our study is concerned with the time effects of a KT campaign on Radiation Oncologists regarding the use of SFRT for bone metastasis. Our study is therefore primarily concerned with the use of interventions for improving of the quality of healthcare, for which SQUIRE 2.0 is well known reporting guideline (24).

\section{Results}

From 1 January 2018 to 31 December 2018, 1,151 courses of palliative RT were administered to patients with a bone metastasis in XXXX. Of these, 135 courses were excluded from the cohort because the metastasis was predominantly soft tissue metastasis with only a minor component of bony invasion. SBRT was utilized for 8 bone metastases, which were excluded from the analysis.

A total of 1,008 courses of palliative RT were included in the analysis (Table 1) with a median age of 67 (range: 5-96), of whom 423 (42.0\%) were women. The most common primary tumor types included: prostate $(26.1 \%)$, lung $(23.6 \%)$, and breast (17.3\%). The most common anatomical sites of bone metastases included: skull/spine (44.6\%), pelvis/proximal femur (32.3\%), and upper extremity (9.2\%). Retreatment to a previously irradiated site was done in $126(12.5 \%)$ cases. 
Table 1

Baseline Characteristics of overall cohort and by fractionation schedule in 2018 (SFRT vs MFRT) (GU: Genitourinary).

\begin{tabular}{|c|c|c|c|c|c|}
\hline \multicolumn{2}{|l|}{ Variable } & $\begin{array}{l}\text { Whole Cohort } \\
(n=1008)\end{array}$ & $\begin{array}{l}\text { SFRT } \\
(n=638)\end{array}$ & $\begin{array}{l}\text { MFRT } \\
(n=370)\end{array}$ & p-value \\
\hline \multicolumn{6}{|l|}{ Patient Characteristics } \\
\hline Age (Median, Range) & & $67(5-96)$ & $\begin{array}{l}69(5- \\
96)\end{array}$ & $\begin{array}{l}65(5- \\
93)\end{array}$ & 0.0008 \\
\hline \multirow{5}{*}{$\begin{array}{l}\text { Charlson Comorbidity } \\
\text { Index }\end{array}$} & 0 & $540(53.6)$ & \multirow{2}{*}{$\begin{array}{l}325 \\
(50.9)\end{array}$} & \multirow{2}{*}{$\begin{array}{l}215 \\
(58.1)\end{array}$} & \multirow[t]{5}{*}{0.034} \\
\hline & 1 & $215(21.3)$ & & & \\
\hline & 2 & 139 (13.8) & $\begin{array}{l}139 \\
(21.8)\end{array}$ & $\begin{array}{l}76 \\
(20.5)\end{array}$ & \\
\hline & \multirow[t]{2}{*}{$\geq 3$} & \multirow[t]{2}{*}{$114(11.3)$} & $\begin{array}{l}89 \\
(14.0)\end{array}$ & $\begin{array}{l}50 \\
(13.5)\end{array}$ & \\
\hline & & & $\begin{array}{l}85 \\
(13.3)\end{array}$ & $29(7.8)$ & \\
\hline \multirow[t]{2}{*}{ Gender } & Female & $423(42.0)$ & $\begin{array}{l}257 \\
(40.3)\end{array}$ & $\begin{array}{l}166 \\
(44.9)\end{array}$ & \multirow[t]{2}{*}{0.155} \\
\hline & Male & $585(58.0)$ & $\begin{array}{l}381 \\
(59.7)\end{array}$ & $\begin{array}{l}204 \\
(55.1)\end{array}$ & \\
\hline \multirow[t]{5}{*}{ ECOG } & $0-1$ & $475(47.1)$ & \multirow{2}{*}{$\begin{array}{l}294 \\
(46.1)\end{array}$} & \multirow{2}{*}{$\begin{array}{l}181 \\
(48.9)\end{array}$} & \multirow[t]{3}{*}{0.193} \\
\hline & 2 & $253(25.1)$ & & & \\
\hline & $3-4$ & $235(23.3)$ & $\begin{array}{l}172 \\
(27.0)\end{array}$ & $\begin{array}{l}81 \\
(21.9)\end{array}$ & \\
\hline & \multirow[t]{2}{*}{ Unknown } & \multirow[t]{2}{*}{$45(4.5)$} & $\begin{array}{l}148 \\
(23.2)\end{array}$ & $\begin{array}{l}87 \\
(23.5)\end{array}$ & \\
\hline & & & $24(3.8)$ & $21(5.7)$ & \\
\hline
\end{tabular}

Disease Characteristics 


\begin{tabular}{|c|c|c|c|c|c|}
\hline Variable & & $\begin{array}{l}\text { Whole Cohort } \\
(n=1008)\end{array}$ & $\begin{array}{l}\text { SFRT } \\
(n=638)\end{array}$ & $\begin{array}{l}\text { MFRT } \\
(n=370)\end{array}$ & $\mathrm{p}$-value \\
\hline \multirow[t]{9}{*}{ Tumour Type } & Prostate & $263(26.1)$ & \multirow{2}{*}{$\begin{array}{l}205 \\
(32.1)\end{array}$} & \multirow{2}{*}{$\begin{array}{l}58 \\
(15.7)\end{array}$} & \multirow[t]{9}{*}{$<0.0001$} \\
\hline & Breast & $174(17.3)$ & & & \\
\hline & Lung & $238(23.6)$ & $\begin{array}{l}107 \\
(16.8)\end{array}$ & $\begin{array}{l}67 \\
(18.1)\end{array}$ & \\
\hline & Hematological & $82(8.1)$ & \multirow{2}{*}{$\begin{array}{l}150 \\
(23.5)\end{array}$} & \multirow{2}{*}{$\begin{array}{l}88 \\
(23.8)\end{array}$} & \\
\hline & Non-prostate GU & $88(8.7)$ & & & \\
\hline & Gastrointestinal & 75 (7.4) & $40(6.3)$ & $\begin{array}{l}42 \\
(11.4)\end{array}$ & \\
\hline & \multirow[t]{3}{*}{ Other } & \multirow[t]{3}{*}{$88(8.7)$} & $39(6.1)$ & 49 & \\
\hline & & & $54(8.5)$ & $32(8.7)$ & \\
\hline & & & & $34(9.2)$ & \\
\hline \multirow[t]{7}{*}{ Site of RT } & Skull and spine & $450(44.6)$ & \multirow{2}{*}{$\begin{array}{l}234 \\
(36.7)\end{array}$} & \multirow{2}{*}{$\begin{array}{l}216 \\
(58.4)\end{array}$} & \multirow[t]{7}{*}{$<0.0001$} \\
\hline & Upper Extremity & $93(9.2)$ & & & \\
\hline & \multirow{2}{*}{$\begin{array}{l}\text { Chest (including } \\
\text { ribs) }\end{array}$} & $68(6.8)$ & $\begin{array}{l}77 \\
(12.1)\end{array}$ & $16(4.3)$ & \\
\hline & & $326(32.3)$ & $48(7.5)$ & $20(5.4)$ & \\
\hline & $\begin{array}{l}\text { Pelvis and proximal } \\
\text { femur }\end{array}$ & $71(7.0)$ & \multirow{2}{*}{$\begin{array}{l}229 \\
(35.9)\end{array}$} & $\begin{array}{l}97 \\
(26.2)\end{array}$ & \\
\hline & \multirow{2}{*}{ Lower extremity } & & & \multirow{2}{*}{$21(5.7)$} & \\
\hline & & & $50(/ .8)$ & & \\
\hline \multirow{3}{*}{$\begin{array}{l}\text { Complicated Bone } \\
\text { Metastasis }\end{array}$} & No & $689(68.4)$ & \multirow{2}{*}{$\begin{array}{l}496 \\
(77.7)\end{array}$} & \multirow{2}{*}{$\begin{array}{l}193 \\
(52.2)\end{array}$} & \multirow[t]{3}{*}{$<0.0001$} \\
\hline & Yes & 319 (31.7) & & & \\
\hline & & & $\begin{array}{l}142 \\
(22.3)\end{array}$ & $\begin{array}{l}177 \\
(47.8)\end{array}$ & \\
\hline \multirow[t]{3}{*}{ Fracture } & No & $746(74.0)$ & 509 & 237 & $<0.0001$ \\
\hline & Yes & $262(26.0)$ & & & \\
\hline & & & $\begin{array}{l}129 \\
(20.2)\end{array}$ & $\begin{array}{l}133 \\
(36.0)\end{array}$ & \\
\hline $\begin{array}{l}\text { Soft Tissue } \\
\text { Component }\end{array}$ & No & $671(66.6)$ & $\begin{array}{l}501 \\
(785)\end{array}$ & $\begin{array}{l}170 \\
(46.0)\end{array}$ & $<0.0001$ \\
\hline & Yes & $337(33.4)$ & & & \\
\hline & & & $\begin{array}{l}137 \\
(21.5)\end{array}$ & $\begin{array}{l}200 \\
(54.1)\end{array}$ & \\
\hline Cord Compression & No & $923(91.6)$ & 616 & 307 & $<0.0001$ \\
\hline & Yes & $85(8.4)$ & & & \\
\hline & & & $22(3.5)$ & $\begin{array}{l}63 \\
(17.0)\end{array}$ & \\
\hline
\end{tabular}




\begin{tabular}{|c|c|c|c|c|c|}
\hline \multicolumn{2}{|l|}{ Variable } & \multirow{2}{*}{$\begin{array}{l}\text { Whole Cohort } \\
(n=1008)\end{array}$} & \multirow{2}{*}{$\begin{array}{l}\text { SFRT } \\
(n=638) \\
633 \\
(99.2)\end{array}$} & \multirow{2}{*}{$\begin{array}{l}\text { MFRT } \\
(n=370) \\
345 \\
(93.2)\end{array}$} & p-value \\
\hline \multirow[t]{2}{*}{$\begin{array}{l}\text { Cauda Equina } \\
\text { Compression }\end{array}$} & No & & & & $<0.0001$ \\
\hline & Yes & $30(3.0)$ & $5(0.8)$ & $25(6.8)$ & \\
\hline \multicolumn{6}{|c|}{ Treatment Characteristics } \\
\hline \multirow[t]{2}{*}{ Retreatment } & & $882(87.5$ & $\begin{array}{l}551 \\
(86.4)\end{array}$ & $\begin{array}{l}331 \\
(89.5)\end{array}$ & \multirow[t]{2}{*}{0.152} \\
\hline & Yes & $126(12.5)$ & $\begin{array}{l}87 \\
(13.6)\end{array}$ & $\begin{array}{l}39 \\
(10.5)\end{array}$ & \\
\hline \multirow[t]{2}{*}{ Post-Operative RT } & No & $958(95.0)$ & $\begin{array}{l}618 \\
(96.9)\end{array}$ & $\begin{array}{l}340 \\
(91.9)\end{array}$ & \multirow[t]{2}{*}{$<0.0001$} \\
\hline & Yes & $50(5.0)$ & 20 (3.1) & $30(8.1)$ & \\
\hline \multirow[t]{2}{*}{ XXXX Site } & Centre A & $865(85.8)$ & $\begin{array}{l}561 \\
(87.9)\end{array}$ & $\begin{array}{l}304 \\
(82.2)\end{array}$ & \multirow[t]{2}{*}{0.011} \\
\hline & Centre B & $143(14.2)$ & $\begin{array}{l}77 \\
(12.1)\end{array}$ & $\begin{array}{l}66 \\
(17.8)\end{array}$ & \\
\hline \multirow{4}{*}{$\begin{array}{l}\text { RO Years in Practice } \\
\text { (yrs) }\end{array}$} & $\leq 6$ & $260(25.8)$ & $\begin{array}{l}142 \\
(22.3)\end{array}$ & \multirow{2}{*}{$\begin{array}{l}118 \\
(31.9)\end{array}$} & \multirow[t]{3}{*}{$<0.0001$} \\
\hline & $7-16$ & $367(36.4)$ & \multirow{2}{*}{$\begin{array}{l}207 \\
(32.5)\end{array}$} & & \\
\hline & $\geq 17$ & $381(37.8)$ & & $\begin{array}{l}160 \\
(43.2)\end{array}$ & \\
\hline & & & $\begin{array}{l}289 \\
(45.3)\end{array}$ & $\begin{array}{l}92 \\
(24.9)\end{array}$ & \\
\hline
\end{tabular}

Bone metastases were classified as complicated in 319 (31.7\%) cases. Amongst the whole cohort, 262 (26.0\%) had fracture, 85 (8.4\%) had spinal cord compression, and $30(3.0 \%)$ had cauda equina compression. Soft tissue extension was observed in 337 (33.4\%) of all bone metastases.

During 2018, the proportion of cases treated with SFRT for all bone metastases (63.3\%) significantly increased over 2017 levels of (59.1\%; z-test $p=0.0034)$, representing an absolute year-over-year change of $+4.2 \%$. Among XXXX's seventeen ROs present during the 2017 KT campaign, nine demonstrated increased year-over-year SFRT utilization for all bone metastases in 2018, while eight demonstrated yearover-year declines in SFRT utilization (Figure 1). Year-over-year changes in SFRT utilization from 2016 (pre-KT campaign) to 2018 (2 years post campaign) for all bone metastases are tabulated in Table 2. For the group of nine ROs with increased SFRT utilization during 2018, who we will term "super adopters", the absolute percent change in SFRT utilization in 2018 over 2017 was $+17.9 \%$, with a range of absolute percentage increases of $+2.2 \%$ to $+47.1 \%$. Conversely, for the group of the eight with decreased utilization during 2018 (which we will term "lapsing-adopters"), the absolute percent decline in SFRT utilization in 2018 over 2017 was $-9.6 \%$, with a range of absolute percentage change of $-1.4 \%$ to $-18.5 \%$. Of the eight 
lapsing adopters, one RO decreased their SFRT utilization to below their baseline pre-KT campaign rate in 2016, while seven have maintained rates above their pre-campaign baseline but below levels seen in the year following the KT campaign (2017).

Table 2

Year-over-year change in proportion of bone metastases treated with SFRT by individual radiation oncologists for all bone metastases. Only clinicians who participated in the KT campaign (17/18) are included.

\begin{tabular}{|llll|}
\hline $\begin{array}{l}\text { De-identified } \\
\text { Radiation } \\
\text { Oncologist }\end{array}$ & $\begin{array}{l}\text { 2016 } \\
\text { USFR } \\
\text { utilization }\end{array}$ & $\begin{array}{l}\text { 2017\% SFRT utilization } \\
\text { (absolute change from } \\
\text { previous year) }\end{array}$ & $\begin{array}{l}\text { 2018 \% SFRT utilization } \\
\text { (absolute \% change from } \\
\text { previous year) }\end{array}$ \\
\hline A & $21 \%$ & $46 \%(+25 \%)$ & $28 \%(-18 \%)$ \\
\hline B & $25 \%$ & $49 \%(+24 \%)$ & $32 \%(-17 \%)$ \\
\hline C & $42 \%$ & $70 \%(+28 \%)$ & $55 \%(-15 \%)$ \\
\hline D & $23 \%$ & $35 \%(+12 \%)$ & $22 \%(-13 \%)$ \\
\hline E & $44 \%$ & $61 \%(+17 \%)$ & $49 \%(-12 \%)$ \\
\hline F & $77 \%$ & $91 \%(+14 \%)$ & $80 \%(-11 \%)$ \\
\hline G & $32 \%$ & $76 \%(+44 \%)$ & $66 \%(-10 \%)$ \\
\hline H & $22 \%$ & $64 \%(+44 \%)$ & $63 \%(-1 \%)$ \\
\hline I & $24 \%$ & $44 \%(+20 \%)$ & $46 \%(+2 \%)$ \\
\hline J & $34 \%$ & $70 \%(+36 \%)$ & $75 \%(+5 \%)$ \\
\hline K & $53 \%$ & $68 \%(+15 \%)$ & $75 \%(+7 \%)$ \\
\hline L & $50 \%$ & $61 \%(+11 \%)$ & $71 \%(+10 \%)$ \\
\hline M & $55 \%$ & $73 \%(+18 \%)$ & $85 \%(+12 \%)$ \\
\hline N & $34 \%$ & $52 \%(+18 \%)$ & $78 \%(+16 \%)$ \\
\hline O & $16 \%$ & $49 \%(+33 \%)$ & $68 \%(+19 \%)$ \\
\hline P & $0 \%$ & $23 \%(+23 \%)$ & $50 \%(+27 \%)$ \\
\hline Q & $23 \%$ & $45 \%(+22 \%)$ & $92 \%(+47 \%)$ \\
\hline
\end{tabular}

When restricting the analysis to those with uncomplicated bone metastases, the proportion of cases treated with SFRT in 2018 for uncomplicated bone metastases (72.0\%) significantly increased over 2017 levels (67.7\%; z-test $p<0.00001)$, representing an absolute year-over-year change of $+4.3 \%$. Among XXXX's seventeen ROs present in the team during the 2017 calendar year, ten demonstrated increases year-overyear SFRT utilization for uncomplicated bone metastases, while seven demonstrated decreased year-overyear SFRT utilization (Figure 2). Year-over-year change in SFRT utilization from 2016 to 2018 for 
uncomplicated bone metastases are described in Table 3. For the group of the ten super adopters, the mean absolute percentage increase in SFRT utilization in 2018 over 2017 was $+19.5 \%$, with a range of absolute percentage increases of $+7.6 \%$ to $+40.8 \%$. Conversely, for the cohort of the seven lapsing adopters, the absolute percent decline in SFRT utilization in 2018 over 2017 was $-10.5 \%$, with a range of absolute percentage declines of $-5.1 \%$ to $-23.6 \%$. Of the seven lapsing-adopters, one RO had decreased SFRT utilization to below their baseline pre-KT campaign rate in 2016, while the other six maintained rates above their pre-campaign baseline but below levels seen in the year following the KT campaign (2017).

Table 3

Year-over-year change in proportion of bone metastases treated with SFRT by individual radiation oncologists for uncomplicated bone metastases. Only clinicians who participated in the KT campaign $(17 / 18)$ are included.

\begin{tabular}{|llll|}
\hline $\begin{array}{l}\text { De-identified } \\
\text { Radiation } \\
\text { Oncologist }\end{array}$ & $\begin{array}{l}\text { 2016 } \\
\text { \%SFR } \\
\text { utilization }\end{array}$ & $\begin{array}{l}\text { 2017 \%SFRT utilization } \\
\text { (absolute change from } \\
\text { previous year) }\end{array}$ & $\begin{array}{l}\text { 2018 \%SFRT utilization } \\
\text { (absolute \% change from } \\
\text { previous year) }\end{array}$ \\
\hline A & $67 \%$ & $79 \%(+12 \%)$ & $52 \%(-27 \%)$ \\
\hline B & $14 \%$ & $46 \%(+34 \%)$ & $22 \%(-24 \%)$ \\
\hline C & $38 \%$ & $92 \%(+54 \%)$ & $74 \%(-18 \%)$ \\
\hline D & $36 \%$ & $55 \%(+19 \%)$ & $44 \%(-11 \%)$ \\
\hline E & $80 \%$ & $95 \%(+15 \%)$ & $84 \%(-11 \%)$ \\
\hline F & $26 \%$ & $39 \%(+13 \%)$ & $29 \%(-10 \%)$ \\
\hline G & $26 \%$ & $73 \%(+47 \%)$ & $68 \%(-5 \%)$ \\
\hline H & $10 \%$ & $59 \%(+49 \%)$ & $67 \%(+8 \%)$ \\
\hline I & $77 \%$ & $71 \% \%(-6 \%)$ & $79 \%(+8 \%)$ \\
\hline J & $46 \%$ & $71 \%(+25 \%)$ & $81 \%(+10 \%)$ \\
\hline K & $64 \%$ & $74 \%(+10 \%)$ & $86 \%(+12 \%)$ \\
\hline L & $67 \%$ & $78 \%(+11 \%)$ & $93 \%(+15 \%)$ \\
\hline M & $48 \%$ & $72 \%(+24 \%)$ & $93 \%(+21 \%)$ \\
\hline N & $24 \%$ & $45 \%(+21 \%)$ & $71 \%(+26 \%)$ \\
\hline O & $0 \%$ & $29 \%(+29 \%)$ & $56 \%(+27 \%)$ \\
\hline P & $29 \%$ & $57 \%(+28 \%)$ & $92 \%(+35 \%)$ \\
\hline Q & $43 \%$ & $48 \%(+5 \%)$ & $(+40 \%)$ \\
\hline
\end{tabular}


In 2018, MFRT was utilized for 370 (36.7\%) of all bone metastases. For patients treated with MFRT, the most common fractionation schedule prescribed were: 20Gy in 5 (77.6\%) and 30Gy in 10 (9.7\%). The proportion of complicated bone metastases were similar between 2018 (31.7\%) and 2017 (32.7\%).

Retreatment rates were also similar year-over-year (2018: 12.5\%; 2017: 13.4\%).

The multivariable logistic regression analysis of the 2018 data (Table 4) revealed the following factors were significantly associated with increased odds of receiving MFRT: hematological primary malignancy (OR $3.66,95 \% \mathrm{Cl} 1.90-7.05)$, males with non-prostate genitourinary (GU) primary malignancy (OR 2.92, $95 \%$ 1.54-5.52), other primary malignancies (includes melanomas, head and neck primaries, gynecological primaries, sarcomas, primaries of the central nervous system, and unknown primaries), OR 2.00, 95\% Cl 1.05-3.78), soft tissue extension (OR 3.80, 95\% Cl 2.68-5.40), and post-operative RT (OR 2.77, $95 \% \mathrm{Cl}$ 1.27-6.01). Univariable logistic regression analysis odds ratios are available in supplemental table 1. 
Table 4

Multivariable Logistic Regression Analysis for Receipt of MFRT in 2018 (Model 1)

\begin{tabular}{|c|c|c|c|}
\hline Variable & & $\begin{array}{l}\text { Multivariable Odds Ratio } \\
(95 \% \mathrm{Cl})\end{array}$ & p-value \\
\hline \multirow[t]{4}{*}{ Age (years) } & 5 to $\leq 57$ & Ref & Ref \\
\hline & 58 to $\leq 66$ & 0.96 (0.61 to 1.50$)$ & 0.608 \\
\hline & 67 to $\leq 75$ & 0.84 (0.52 to 1.35$)$ & 0.519 \\
\hline & $\geq 76$ & 0.78 (0.48 to 1.27$)$ & 0.484 \\
\hline \multirow[t]{2}{*}{ Sex } & Female & Ref & Ref \\
\hline & Male & 1.13 (0.75 to 1.69$)$ & 0.558 \\
\hline \multirow[t]{3}{*}{ ECOG Performance Status } & $0-1$ & Ref & Ref \\
\hline & 2 & 0.59 (0.40 to 0.87$)$ & 0.007 \\
\hline & $3-4$ & 0.57 (0.38 to 0.86$)$ & 0.007 \\
\hline \multirow[t]{4}{*}{ Charlson Score } & 0 & Ref & Ref \\
\hline & 1 & 0.73 (0.48 to 1.10$)$ & 0.129 \\
\hline & 2 & 0.77 (0.47 to 1.24$)$ & 0.280 \\
\hline & $\geq 3$ & 0.49 (0.27 to 0.86$)$ & 0.014 \\
\hline \multirow[t]{7}{*}{ Tumour Type } & Prostate & Ref & Ref \\
\hline & Breast & 1.71 (0.86 to 3.40$)$ & 0.127 \\
\hline & Lung & 1.63 (0.98 to 2.72 ) & 0.060 \\
\hline & Hematological & 3.66 (1.90 to 7.05$)$ & $<0.0001$ \\
\hline & $\begin{array}{l}\text { Non-Prostate } \\
\text { GU }\end{array}$ & 2.92 (1.54 to 5.52$)$ & $<0.0001$ \\
\hline & Gostrointoctinol & 1.73 (0.88 to 3.42$)$ & 0.115 \\
\hline & Other & 2.00 (1.05 to 3.78$)$ & 0.034 \\
\hline \multirow[t]{5}{*}{ Treatment Site } & Skull/Spine & Ref & Ref \\
\hline & Upper Extremity & 0.30 (0.16 to 0.58$)$ & $<0.0001$ \\
\hline & Thorax & 0.40 (0.20 to 0.78$)$ & 0.007 \\
\hline & Pelvis & 0.61 (0.43 to 0.89$)$ & 0.010 \\
\hline & $\begin{array}{l}\text { Lower } \\
\text { Extremity }\end{array}$ & 0.54 (0.27 to 1.08$)$ & 0.080 \\
\hline
\end{tabular}




\begin{tabular}{|c|c|c|c|}
\hline Variable & & $\begin{array}{l}\text { Multivariable Odds Ratio } \\
(95 \% \mathrm{Cl})\end{array}$ & p-value \\
\hline \multirow[t]{2}{*}{ Complicated Bone Metastasis } & Uncomplicated & Ref & Ref \\
\hline & Complicated & 1.69 (1.18 to 2.41$)$ & 0.004 \\
\hline \multirow[t]{2}{*}{ Soft Tissue Extension } & No & Ref & Ref \\
\hline & Yes & 3.80 (2.68 to 5.40$)$ & $<0.0001$ \\
\hline \multirow[t]{2}{*}{ Retreatment } & No & Ref & Ref \\
\hline & Yes & 0.67 (0.41 to 1.09$)$ & 0.105 \\
\hline \multirow[t]{2}{*}{ Post-Operative RT } & No & Ref & Ref \\
\hline & Yes & 2.77 (1.27 to 6.01$)$ & 0.010 \\
\hline \multirow[t]{2}{*}{ XXXX Site } & Centre A & Ref & Ref \\
\hline & Centre B & 1.30 (0.78 to 2.15$)$ & 0.308 \\
\hline \multirow{3}{*}{$\begin{array}{l}\text { Radiation Oncologist Years in } \\
\text { Practice }\end{array}$} & $\leq 6$ & Ref & Ref \\
\hline & 7 to 16 & 0.80 (0.51 to 1.24$)$ & 0.312 \\
\hline & $\geq 17$ & 0.30 (0.19 to 0.48$)$ & $<0.0001$ \\
\hline
\end{tabular}

On multivariable logistic regression of the combined 2017/2018 dataset (Supplemental Table 2) including all of the covariates used in the 2017 model, patients treated in 2018 had significantly lower odds of receiving MFRT compared to patients treated in 2017 after adjusting for potential confounding variables (OR $0.70,95 \% \mathrm{Cl} 0.56-0.87)$.

\section{Discussion}

This study found that radiation oncologist SFRT prescription behaviour imparted by KT campaigns demonstrated two important time-dependent characteristics in the second year removed from the KT campaign. Firstly, the rate of uptake in institution-wide SFRT utilization for all bone metastases has slowed from a $21.1 \%$ absolute increase in 2017 (0-12 months after the campaign) (19) to a $4.2 \%$ absolute increase in 2018 (12-24 months after the campaign; $p=0.0034)$, perhaps indicating that SFRT utilization is approaching its maximum asymptote, or indicating the need for adapting our campaign message to continue reinforcing SFRT utilization. Secondly, a dichotomy has emerged whereby half of the ROs ( 9 of 17) who participated in the KT campaign continued to demonstrate year-over-year increases in their SFRT utilization for bone metastases in 2018, while the other half of the ROs ( 8 of 17) demonstrated a yearover-year decline in SFRT utilization in 2018 from their 2017 peak SFRT utilization rates. This is in contrast to the first 12 months after the campaign, when all 17 ROs who participated in the KT campaign demonstrated increased year-over-year SFRT utilization (19). After controlling for potential confounding covariates included in Supplemental Table 1, year of treatment (2018 versus 2017) remained as a 
statistically significant variable $(\mathrm{p}=0.001)$. Thus, positive impact of the KT campaign has not only decreased in momentum in the second year period post completion of the KT campaign but have also been carried by a smaller subgroup of ROs whereas others RO has lapsed into old MFRT prescribing habits.

The decline in SFRT utilization observed in some of the ROs in our cohort two years post KT intervention may mirror the findings of a study conducted in British Columbia, Canada. In their jurisdiction, the authors examined SFRT utilization rate changes following a KT campaign in British Columbia. They also noted that SFRT use trended downwards after the initial uptick associated with their KT intervention (24). The exact reason for these observed declines in SFRT utilization two years removed from the KT intervention both in the case of British Columbia and XXXX are unknown but may be explained, in part, by several observations in the literature. Time-dependent loss of utilization of guideline compliant behaviour derived from KT campaigns has been observed in other KT milieus. In an observational audit study tracking hand hygiene compliance after a hand hygiene KT campaign in intensive care units, hand hygiene compliance increased immediately after the campaign, then subsequently declined during a two-year follow-up period as fewer intensive care units maintained strong compliance while other units returned to baseline lower compliance (25). In another observational audit study tracking a hand hygiene KT campaign, initial hand hygiene compliance rose over the one-year period after starting the campaign, then decreased after the initial uptick (26). These examples of time-dependent loss of KT derived behaviours suggest that the KT message compliance decays over time for healthcare practitioners and our findings suggest that radiation oncologists are not immune to forgetting lessons learned via KT campaigns. It is therefore a reasonable hypothesis that that re-exposing radiation oncologists to periodic KT refreshers may be helpful. It is also possible that lapsing radiation oncologists were overexposed to KT interventions leading to tuning out of the KT messaging, a phenomenon known as "messaging fatigue" or "campaign fatigue". Observations in the literature suggest that healthcare professionals who are regularly overexposed to KT campaigns are not immune to messaging fatigue (28). Exposure of healthcare workers to excessive KT messaging has been associated with information overload and mental fatigue resulting in reduced ability to distinguish important messages from irrelevant ones $(29,30)$ which in turn can lead to suboptimal care decisions and clinician behaviour (28). In a randomized control study in the State of Washington, the recall of a certain public health message sent to healthcare providers was inversely proportional to the mean number of messages received per week, and the odds of recall decreased with the increase of public health messages per week (31) suggesting that KT messaging faded into "background noise". Interestingly, that study was conducted during the H1N1 Influenza pandemic, which was associated with a dramatic increase in public health messages sent to healthcare providers, and recall rates improved as the overall message load on practitioners decreased to pre-pandemic levels (31). This corollary lesson from the H1N1 Influenza pandemic suggests that messaging fatigue is a potential outcome of overexposure to KT interventions, and one that administrators would need to keep in mind when determining how many interventions to expose radiation oncologists to with respect to SFRT use.

Although our study demonstrated the presence of a group of super adopters and another group of lapsing adopters of SFRT for bone metastases, this division into two subgroups of ROs did not exist in retrospect 
prior to the 2018 results. Neither subgroup, when analyzed retrospectively (data not shown), has consistently outperformed or underperformed the other subgroup in terms of SFRT utilization. Effective KT requires early addressal of barriers to knowledge adoption (16). It is possible that the group of lapsingadopters may have encountered new and unique barriers to knowledge adoption pertaining to SFRT during year 2 of follow-up which may not have been addressed in the original intervention. Keeping these two subgroups in mind for future analyses of SFRT utilization in XXXX may prove useful to identify and analyze barriers to resistance to the KT campaign messaging and improve upon the gains already achieved. Often, the drivers of maintenance behavior in KT are different from the drivers of initiation (32), and successful campaigns must recognize this difference and adapt to a changing local context to remain relevant and sustainable over time (33).

Although the KT campaign's original goal was reaching an institution-level target of SFRT utilization for $60 \%$ of all bone metastases, as suggested by Tiwana et. al. in a similar study in British Columbia (34), the results of this study suggest that this target may need to be revisited. Although the 2018 institution-level SFRT utilization for all bone metastases is $63.3 \%$, we observed that only $72 \%$ of uncomplicated bone metastases received SFRT in 2018. Thus, there remains a considerable subgroup of uncomplicated bone metastases (approximately $20 \%$ of the whole cohort) for whom the SFRT guideline compliance can be improved. Moreover, there is growing evidence that SFRT is a clinically acceptable and non-inferior option to MFRT for subsets of patients with complicated bone metastases, specifically those with spinal cord compressions (35). Thus, we judge that under ideal circumstances, the maximal proportion of all bone metastases which could and should be treated with SFRT in a guideline and evidence-complaint manner is approximately $80 \%$. Our study identified several clinical subgroups of patients with lower proportions of SFRT compared to the rest of the patient population of patients with bone metastases, namely patients with soft tissue extension portions to their bone metastasis, RT prescribed post-operatively, hematological cancer primaries, non-prostate GU cancer primaries, and other cancer primaries (melanomas, head and neck primaries, gynecological primaries, sarcomas, primaries of the central nervous system, and unknown primaries). Future KT efforts will have to reaffirm the concept that SFRT for uncomplicated bone metastases is recommended for all clinical subgroups of patients including these aforementioned groups. To this end, we intend to continue to monitor compliance with SFRT utilization through audit and ad hoc feedback in an effort to keep the KT campaign message sustainable and relevant.

There are several limitations to this study. Firstly, the retrospective nature of our study cannot directly assess causality between the KT campaign and the observed effects on SFRT utilization. To mitigate this limitation the combined 2017/2018 multivariable logistic regression analysis was built to assess the impact of treatment year on the outcome of receipt of SFRT while adjusting for many other potentially confounding variables in the model. Secondly, the decision regarding if a bone metastasis was complicated or uncomplicated prior to treatment was left to the discretion of individual ROs (i.e., it was not centrally reviewed or controlled), and thus may have had implications on the choice of SFRT vs MFRT for individual ROs that was not captured when applying the definition of complicated employed in this study. Thirdly, since data regarding postoperative palliative RT was only collected in 2018 , and not in 2017, we are unable to determine if any changes in proportion of patients treated postoperatively acted 
as a confounder in the year-over-year utilization of SFRT; although this risk is expected to be minimal since postoperative RT consisted of only 5\% of all bone metastases treated in 2018.

\section{Conclusion}

The rate of increase of SFRT utilization in XXXX 2 years post KT intervention decreased compared to the immediate post KT-time period and a significant proportion of ROs lapsed to lower SFRT utilization levels. Our findings suggest that KT-derived RO SFRT prescribing behaviour is time-perishing in nature. Further reinforcement of KT messaging and continued SFRT utilization audits are therefore warranted.

\section{Abbreviations}

SFRT $=$ Single Fraction Radiotherapy

MFRT = Multifraction Radiotherapy

$\mathrm{RO}=$ Radiation Oncologist

SBRT = Stereotactic Body Radiotherapy

$\mathrm{KT}=$ Knowledge Translation

\section{Declarations}

Ethical Approval \& Consent to Participate: This study was conducted with the prior written approval of the University of XXXX Health Research Ethics Board (Approval \#: HS20808), and the XXXX Research Resource Impact Committee (Approval \#: 2017-020).

Consent for Publication: N/A

Availability of Data \& Materials: Data utilized and analyzed in this study is available upon reasonable request from the corresponding author.

Competing Interests: The authors declare no competing interests.

Funding: Salary support for this study was provided by The University of XXX Bachelor of Science in Medicine Program.

Authors' Contributions: JK and SS conceptualized the study, performed data extraction, data analysis, manuscript drafting and editing. $\mathrm{NH}, \mathrm{YTC}, \mathrm{JB}$ conducted data extraction, data cleaning, and edited the manuscript. RK, BB, AC, AD, JB, MN, WH, SR, AO, and KT helped facilitate the Knowledge Translation Campaign featured in this study and edited the manuscript.

\section{References}


1. Rich SE, Chow R, Raman S, et al. Update of the systematic review of palliative radiation therapy fractionation for bone metastases. Radiother Oncol. 2018;126(3):547-57. doi:10.1016/j.radonc.2018.01.003.

2. Bedard G, Hoskin P, Chow E. Overall response rates to radiation therapy for patients with painful uncomplicated bone metastases undergoing initial treatment and retreatment. Radiother Oncol. 2014;112(1):125-7. doi:10.1016/j.radonc.2014.06.015.

3. Chow $E$, van der Linden $Y M$, Roos $D$, et al. Single versus multiple fractions of repeat radiation for painful bone metastases: A randomised, controlled, non-inferiority trial. The Lancet Oncology. 2014;15(2):164-71. doi:10.1016/S1470-2045(13)70556-4.

4. Pin Y, Paix A, Le Fèvre C, Antoni D, Blondet C, Noël G. A systematic review of palliative bone radiotherapy based on pain relief and retreatment rates. Crit Rev Oncol/Hematol. 2018;123:132-7. doi:10.1016/j.critrevonc.2018.01.006.

5. Howell DD, James JL, Hartsell WF, et al. Single-fraction radiotherapy versus multifraction radiotherapy for palliation of painful vertebral bone metastases - Equivalent efficacy, less toxicity, more convenient: A subset analysis of Radiation Therapy Oncology Group trial 97-14. Cancer. 2013;119(4):888-96. doi:10.1002/cncr.27616.

6. van den Hout WB, van der Linden YM, Steenland E, et al. Single- versus multiple-fraction radiotherapy in patients with painful bone metastases: Cost-utility analysis based on a randomized trial. J Natl Cancer Inst. 2003;95(3):222-9. doi:10.1093/jnci/95.3.222.

7. Konski A, James J, Hartsell W, et al. Economic analysis of Radiation Therapy Oncology Group 97-14: Multiple versus single fraction radiation treatment of patients with bone metastases. American Journal of Clinical Oncology: Cancer Clinical Trials. 2009;32(4):423-8.

doi:10.1097/COC.0b013e31818da9f7.

8. Steenland $\mathrm{E}$, Leer $\mathrm{J}$, Van Houwelingen $\mathrm{H}$, et al. The effect of a single fraction compared to multiple fractions on painful bone metastases: A global analysis of the Dutch Bone Metastasis Study. Radiother Oncol. 1999;52(2):101-9. doi:10.1016/S0167-8140(99)00110-3.

9. Pollicino CA, Turner SL, Roos DE, O'Brien PC. Costing the components of pain management. Analysis of Trans-Tasman Radiation Oncology Group trial (TROG 96.05): One versus five fractions for neuropathic bone pain. Radiother Oncol. 2005;76(3):264-9. doi:10.1016/j.radonc.2005.07.003.

10. Lutz S, Berk L, Chang E, et al. Palliative radiotherapy for bone metastases: An ASTRO evidence-based guideline. Int J Radiat Oncol Biol Phys. 2011;79(4):965-76. doi:10.1016/j.ijrobp.2010.11.026.

11. Wu JSY, Wong RKS, Lloyd NS, Johnston M, Bezjak A, Whelan T. Radiotherapy fractionation for the palliation of uncomplicated painful bone metastases - An evidence-based practice guideline. BMC Cancer. 2004;4:71. doi:10.1186/1471-2407-4-71.

12. Janjan N, Lutz ST, Bedwinek JM, et al. Therapeutic guidelines for the treatment of bone metastasis: A report from the American college of radiology appropriateness criteria expert panel on radiation oncology. Journal of Palliative Medicine. 2009;12(5):417-26. doi:10.1089/jpm.2009.9633. 
13. Fairchild A, Barnes E, Ghosh S, et al. International Patterns of Practice in Palliative Radiotherapy for Painful Bone Metastases: Evidence-Based Practice? Int J Radiat Oncol Biol Phys. 2009;75(5):150110. doi:10.1016/j.jijrobp.2008.12.084.

14. Hartsell WF, Konski AA, Lo SS, Hayman JA. Single Fraction Radiotherapy for Bone Metastases: Clinically Effective, Time Efficient, Cost Conscious and Still Underutilized in the United States? Clin Oncol. 2009;21(9):652-4. doi:10.1016/j.clon.2009.08.003.

15. Tran K, Rahal R, Brundage M, et al. Use of low-value radiotherapy practices in Canada: An analysis of provincial cancer registry data. Current Oncology. 2016;23(5):351-5. doi:10.3747/co.23.3359.

16. Curran JA, Grimshaw JM, Hayden JA, Campbell B. Knowledge translation research: The science of moving research into policy and practice. Journal of Continuing Education in the Health Professions. 2011;31(3):174-80. doi:10.1002/chp.20124.

17. Levinson W, Huynh T. Engaging physicians and patients in conversations about unnecessary tests and procedures: Choosing Wisely Canada. CMAJ. 2014;186(5):325-6. doi:10.1503/cmaj.131674.

18. Mitera G, Earle C, Latosinsky S, et al. Choosing Wisely Canada cancer list: ten low-value or harmful practices that should be avoided in cancer care. Journal of oncology practice. 2015;11(3):e296-303. doi:10.1200/JOP.2015.004325.

19. Shahhat S, Hanumanthappa N, Chung YT, et al. Do Coordinated Knowledge Translation Campaigns Persuade Radiation Oncologists to Use Single-Fraction Radiation Therapy Compared With MultipleFraction Radiation Therapy for Bone Metastases? Int J Radiat Oncol Biol Phys. 2020;S03603016(20):34214-0. doi:10.1016/j.jijobp.2020.08.056.

20. Tricco AC, Antony J, Ivers NM, et al. Effectiveness of quality improvement strategies for coordination of care to reduce use of health care services: A systematic review and meta-analysis. CMAJ. 2014;186(15):E568-78. doi:10.1503/cmaj.140289.

21. Tricco AC, Ashoor HM, Cardoso R, et al. Sustainability of knowledge translation interventions in healthcare decision-making: a scoping review. Implementation Science. 2015;11(1):55. doi:10.1186/s13012-016-0421-7.

22. Ashworth A, Kong W, Chow E, MacKillop WJ. Fractionation of palliative radiation therapy for bone metastases in Ontario: Do practice guidelines guide practice? Int J Radiat Oncol Biol Phys. 2016;94(1):31-9. doi:10.1016/j.jjrobp.2015.07.2291.

23. Cheon PM, Wong E, Thavarajah N, et al. A definition of "uncomplicated bone metastases" based on previous bone metastases radiation trials comparing single-fraction and multi-fraction radiation therapy. Journal of Bone Oncology. 2015;4(1):13-7. doi:10.1016/j.jbo.2014.12.001.

24. Ogrinc G, Davies L, Goodman D, Batalden P, Davidoff F, Stevens D. SQUIRE 2.0 (Standards for QUality Improvement Reporting Excellence): revised publication guidelines from a detailed consensus process. BMJ Qual Saf. 2016;25(12):986-92. doi:10.1136/BMJQS-2015-004411.

25. Olson R, Chan M, Minhas N, et al. Programmatic Comparison and Dissemination of an Audit of Single-fraction Radiation Therapy Prescribing Practices for Bone Metastases is Associated with a 
Meaningful and Lasting Change in Practice on a Population Level. Int J Radiat Oncol Biol Phys. 2018;102(2):325-9. doi:10.1016/j.jirobp.2018.06.001.

26. Biswal M, Rajpoot S, Dhaliwal N, Appananavar SB, Taneja N, Gupta AK. Evaluation of the short-term and long-term effect of a short series of hand hygiene campaigns on improving adherence in a tertiary care hospital in India. Am J Infect Control. 2014;42(9):1009-10. doi:10.1016/j.ajic.2014.05.025.

27. Seto WH, Yuen SWS, Cheung CWY, Ching PTY, Cowling BJ, Pittet D. Hand hygiene promotion and the participation of infection control link nurses: An effective innovation to overcome campaign fatigue. Am J Infect Control. 2013;41(12):1281-3. doi:10.1016/j.ajic.2013.04.011.

28. Beasley JW, Wetterneck TB, Temte J, et al. Information chaos in primary care: Implications for physician performance and patient safety. J Am Board Fam Med. 2011;24(6):745-51. doi:10.3122/jabfm.2011.06.100255.

29. Glassman PA, Simon B, Belperio P, Lanto A. Improving recognition of drug interactions benefits and barriers to using automated drug alerts. Med Care. 2002;40(12):1161-71. doi:10.1097/00005650200212000-00004.

30. van der Sijs H, Aarts J, Vulto A, Berg M. Overriding of drug safety alerts in computerized physician order entry. J Am Med Inform Assoc. 2006;13(2):138-47. doi:10.1197/jamia.M1809.

31. Baseman JG, Revere D, Painter I, Toyoji M, Thiede H, Duchin J. Public health communications and alert fatigue. BMC Health Services Research. 2013;13(1):295. doi:10.1186/1472-6963-13-295.

32. White M, Kwasnicka D, Dombrowski SU, White M. Theoretical explanations for maintenance of behavior change: a systematic review of behavior theories Theoretical explanations for maintenance of behaviour change : a systematic review of behaviour theories. Health Psychology Review. 2016;10(3):277-96.

33. Lennox L, Maher L, Reed J. Navigating the sustainability landscape: a systematic review of sustainability approaches in healthcare. Implementation Science: IS. 2018;13(1). doi:10.1186/S13012-017-0707-4.

34. Tiwana MS, Barnes M, Yurkowski E, Roden K, Olson RA. Incidence and treatment patterns of complicated bone metastases in a population-based radiotherapy program. Radiother Oncol. 2016;118(3):552-6. doi:10.1016/j.radonc.2015.10.015.

35. Hoskin PJ, Hopkins K, Misra V, et al. Effect of Single-Fraction vs Multifraction Radiotherapy on Ambulatory Status among Patients with Spinal Canal Compression from Metastatic Cancer: The SCORAD Randomized Clinical Trial. JAMA - Journal of the American Medical Association. 2019;322(21):2084-94. doi:10.1001/jama.2019.17913.

\section{Figures}


$100 \%$

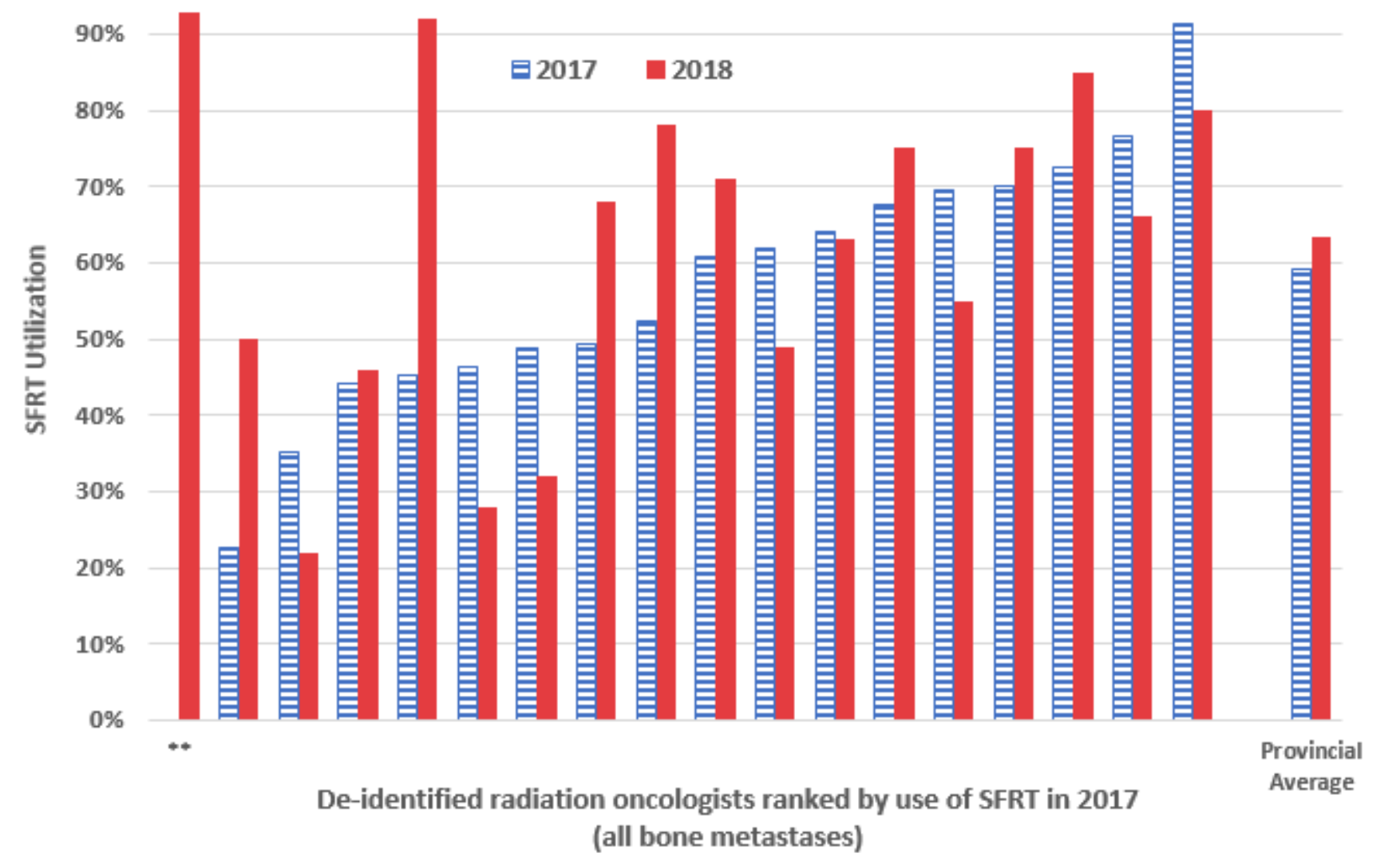

Figure 1

Proportion of SFRT utilized in by de-identified individual radiation oncologists for all bone metastases in 2017 and 2018 in XXXX (**: Radiation oncologist joined the team in 2018, and has no 2017 comparison point) 


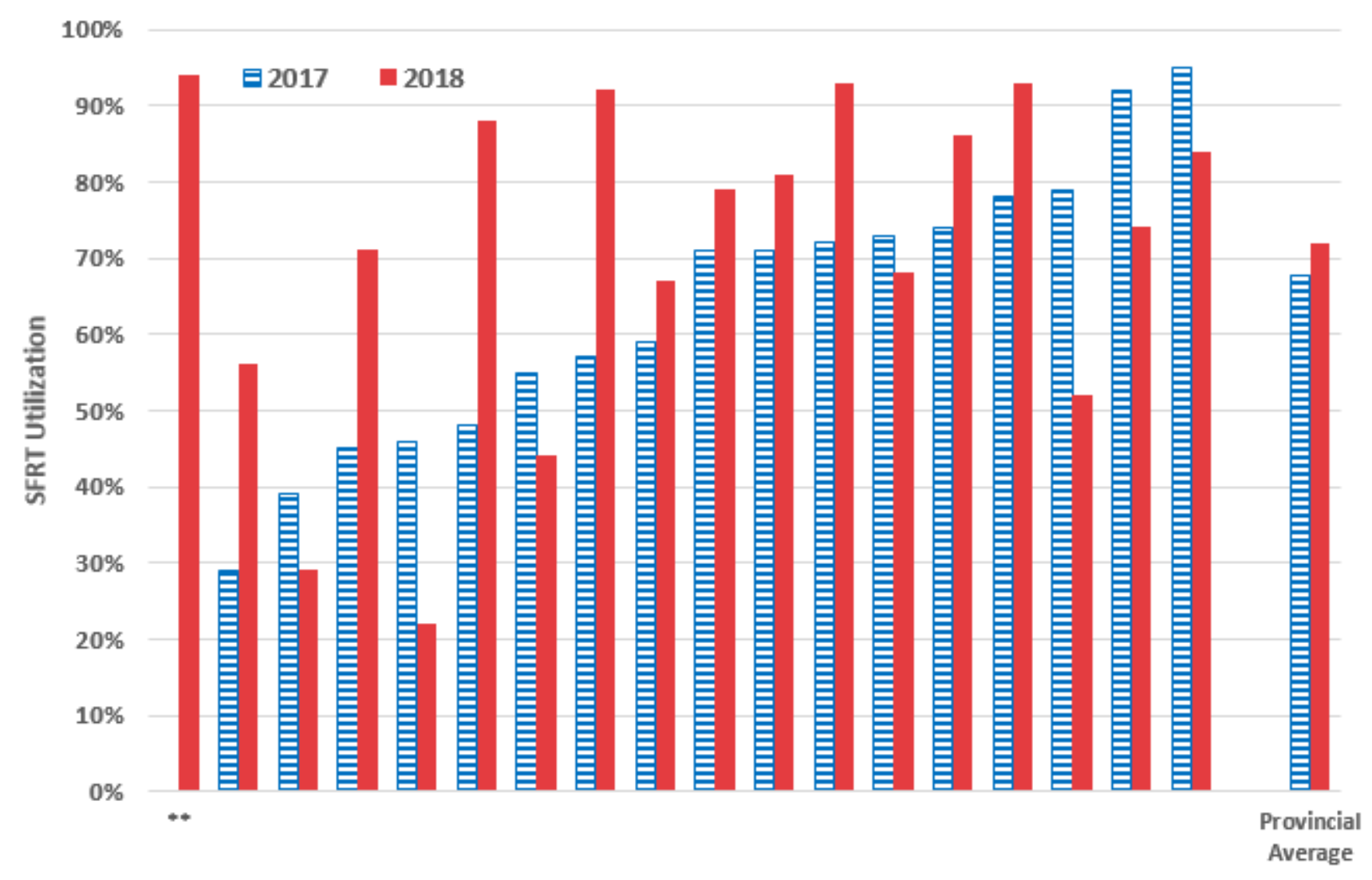

De-identified radiation oncologists ranked by use of SFRT in 2017

(uncomplicated bone metastases)

Figure 2

Proportion of SFRT utilized by de-identified individual radiation oncologists for uncomplicated bone metastases in 2017 and 2018 in XXXX ( $* *$ : Radiation oncologist joined the team in 2018, and has no 2017 comparison point)

\section{Supplementary Files}

This is a list of supplementary files associated with this preprint. Click to download.

- SQUIRE2.0Checklist.docx

- SuppTable1blinded.docx

- SuppTable2blinded.docx 